\title{
High-Frequency Absorbing Performances of Carbonyl Iron/MnZn Ferrite/PVC Polymer Composites
}

\author{
R. DOSOUdiL* AND M. UŠÁKOVÁ
}

Institute of Electrical Engineering, Faculty of Electrical Engineering and Information Technology, Slovak University of Technology, Ilkovičova 3, 81219 Bratislava, Slovakia

We have prepared composite materials with a mixture of carbonyl iron (CI) and manganese-zinc ferrite (MnZn) as filler and polyvinylchloride (PVC) as polymer matrix, and then electromagnetic wave absorption properties of $\mathrm{CI} / \mathrm{MnZn} / \mathrm{PVC}$ composites have been studied in the frequency range from $10 \mathrm{MHz}$ to $6.5 \mathrm{GHz}$. Increasing carbonyl iron loading (to the detriment of $\mathrm{MnZn}$ ferrite) results in the rise of permeability and magnetic resonance loss (especially in $\mathrm{GHz}$ frequency range) which leads to the shift of absorption peak towards lower frequency and to the decrease of matching thickness. On the contrary, increasing MnZn ferrite loading (to the detriment of carbonyl iron) results in higher absorption bandwidth. The obtained results indicate that the prepared flexible composites may be useful as thin and/or wideband microwave absorbers.

DOI: 10.12693/APhysPolA.131.687

PACS/topics: 75.50.Gg, 75.50.Bb, 76.50.+g, 75.78.-n, 72.80.Tm, 78.20.Ci, 41.20.Jb

\section{Introduction}

With the rapid advances and broad implementation of radio communication and computer technology, and with the ongoing miniaturization of electronic equipments, there is an increased functionality of high-frequency absorbing materials that can provide effective shielding of electromagnetic interferences (EMI), especially in microwave frequency range (over $500 \mathrm{MHz}$ ). High-frequency absorbers with defined absorption characteristics have been developed to eliminate EMI, and composites of soft magnetic and insulating materials are particularly focused with much interest in this sphere [1,2]. CI and MnZn are magnetic materials which exhibit excellent electromagnetic wave absorption properties and many studies on CI or MnZn composites as shielding materials have been published [3-7]. Polymer-based composites have low density and can provide connectivity among the fillers and hence are best suitable for shielding applications. PVC polymer provides flexibility to the composite in addition to its appropriate chemical and dielectric properties and is therefore chosen as the matrix. For the present investigation, the combined CI/MnZn magnetic filler were added into the PVC matrix to prepare $\mathrm{CI} / \mathrm{MnZn} / \mathrm{PVC}$ composite samples with different filler volume fractions and the electromagnetic wave absorption properties of these composites were studied to explore the potential application of these composites.

\section{Experimental}

The composite samples were prepared by mixing commercially available carbonyl iron - type EN, hard grade, containing $97.5 \%$ of iron, $0.9 \%$ of carbon, $1.0 \%$ of nitrogen and $0.5 \%$ of oxygen (BASF company, Germany) and $\mathrm{MnZn}$ ferrite with composition $\mathrm{Mn}_{0.52} \mathrm{Zn}_{0.43} \mathrm{Fe}_{2.05} \mathrm{O}_{4}$

*corresponding author; e-mail: rastislav.dosoudil@stuba.sk
(Pramet Šumperk company, Czech Republic) in different filler volume ratios of 1:0, 0.75:0.25, 0.5:0.5, 0.25:0.75, and $0: 1$ in polyvinylchloride (PVC) polymeric matrix. Then, hot pressing was carried out. Blend of metal/ferrite filler with $\mathrm{PVC}$ was plasticized and fired at $135^{\circ} \mathrm{C}$ and $5 \mathrm{MPa}$. Curing time was $30 \mathrm{~min}$. The total volume concentration of combined $\mathrm{CI} / \mathrm{MnZn}$ filler in composites was kept at 50 vol.\%. The pressed composites were prepared in the form of rings with an outer diameter of $7 \mathrm{~mm}$, an inner diameter of $3.05 \mathrm{~mm}$ and a height of $2-3 \mathrm{~mm}$.

The microstructural aspects such as surface morphology, particle size and chemical composition of the carbonyl iron and MnZn ferrite powders were estimated using a scanning electron microscope (JEOL JSM-7500F).

Variation of complex (relative) permeability $\mu=\mu^{\prime}-$ $j \mu^{\prime \prime}$ versus frequency $f$ in the range from $10 \mathrm{MHz}$ to $6.5 \mathrm{GHz}$ was studied by means of a combined impedance/network analysis method using a vector network analyser (Keysight E5063A). During impedance measurements (carried out in the range $10 \mathrm{MHz}-1 \mathrm{GHz}$ ), a ring sample was inserted into a coaxial short-circuit sample holder (16454A) and the complex permeability was evaluated from measured complex impedances [8]: $\mu=$ $\mu^{\prime}-j \mu^{\prime \prime}=1+\left(Z-Z_{\text {air }}\right) /\left(j h \mu_{0} f \ln \left(D_{1} / D_{2}\right)\right)$, where $Z$ and $Z_{\text {air }}$ are the input complex impedances of the $16454 \mathrm{~A}$ holder with and without a toroidal sample, respectively, $h$ is the height of the sample, $\mu_{0}=4 \pi \times 10^{-7} \mathrm{H} / \mathrm{m}$ is the permeability of free space, $f$ is the frequency, and $D_{1}$ and $D_{2}$ are the outer and inner diameters of the sample. Network analysis method was performed in microwave band $(100 \mathrm{MHz}-6.5 \mathrm{GHz})$ using standard $7 \mathrm{~mm}$ coaxial transmission line holder and the complex permeability was calculated from measured reflection and transmission parameters.

Electromagnetic wave absorption parameters (derived from the frequency dependences of return loss RL) such as the matching thickness $d_{m}$, matching frequency $f_{m}$, 
bandwidth $\Delta f$ for $\mathrm{RL} \leq-20 \mathrm{~dB}$ and the minimum of return loss $\mathrm{RL}_{\min }$ were obtained by numerical simulations in Mathcad software.

\section{Results and discussion}

SEM images of carbonyl iron are shown in Fig. 1 (a - surface morphology of particle and b - structure of particle). It can be seen that the carbonyl iron particles have spherical shape with structure similar to onion bulb. The particle size varies in the interval $1-5 \mu \mathrm{m}$. SEM image of spinel MnZn ferrite is depicted in Fig. 1c. The MnZn ferrite particles have irregular (polyhedral) shape with the size range of $10-80 \mu \mathrm{m}$.
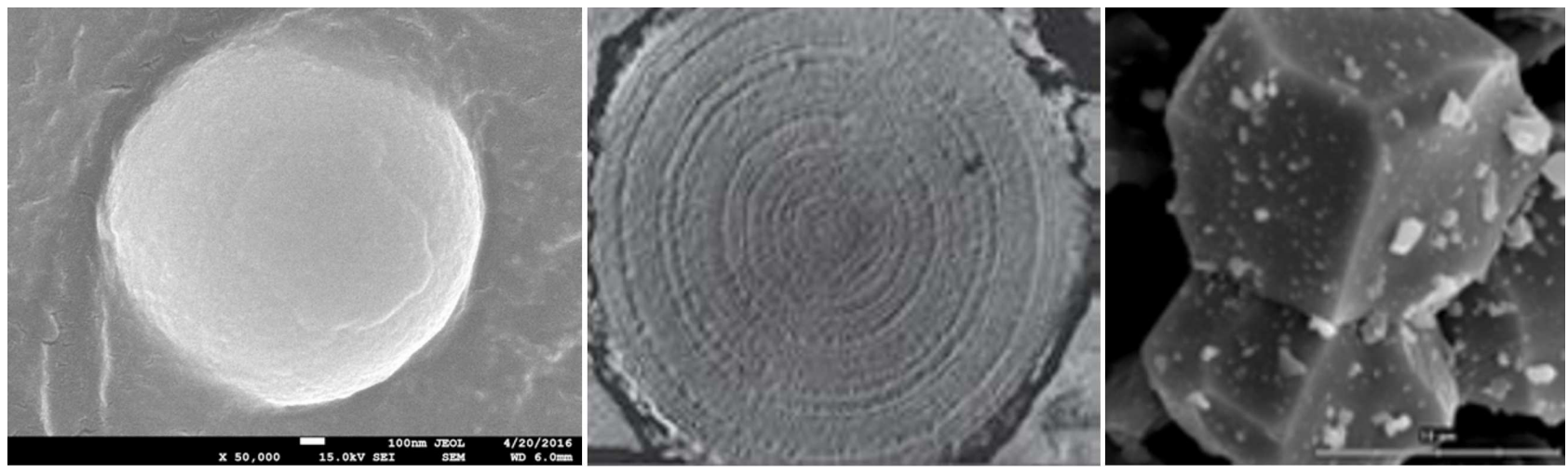

Fig. 1. SEM photographs of (a) carbonyl iron, (b) its microstructure, and (c) MnZn ferrite.

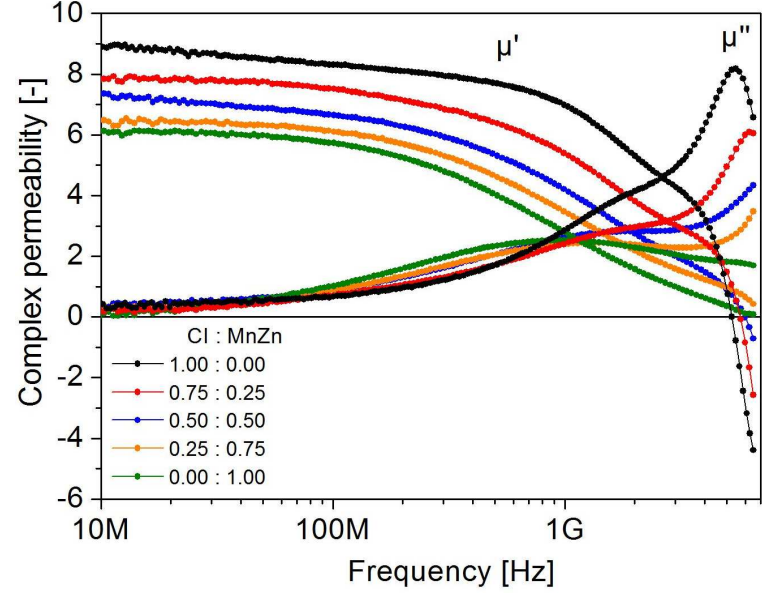

Fig. 2. Frequency dependences of real and imaginary parts of complex (relative) permeability for prepared $\mathrm{CI} / \mathrm{MnZn} / \mathrm{PVC}$ composites with different filler volume ratios.

Figure 2 presents the variation of complex (relative) permeability $\mu=\mu^{\prime}-j \mu^{\prime \prime}$ with frequency $f$ for fabricated composite samples. The measured responses showed a dispersive character of $\mu-f$ dependences. The frequency dispersion of complex permeability changed continuously with the change of filler volume ratio between two types of fillers: from relaxation type observed in twophase $\mathrm{MnZn} / \mathrm{PVC}$ composite to strong resonance type observed in two-phase CI/PVC sample. The value of $\mu^{\prime}$ increased from about 6 for $\mathrm{MnZn} / \mathrm{PVC}$ sample to about 9 for CI/PVC one. The obtained frequency dispersion of $\mu$ is principally caused by the domain wall resonance (vibrating Bloch's walls due to the force acting on walls in the presence of high frequency external ac electromagnetic field), the natural ferromagnetic and/or ferrimagnetic resonance (also known as the spin precession resonance: the forced precession of magnetization vectors in domains due to the presence of effective magnetic anisotropy), and the relaxation of magnetization [8-10]. Due to a low resistivity of carbonyl iron $\left(\approx 10^{-7} \Omega \mathrm{m}\right)$ and MnZn ferrite $(\approx 1 \Omega \mathrm{m})$, also the eddy current effect could influence the measured permeability spectra. For all samples, the real part $\mu^{\prime}$ of $\mu$ went down and the imaginary part $\mu^{\prime \prime}$ of $\mu$ increased with growing frequency $f$. The maximum in $\mu^{\prime \prime}-f$ dependence for $\mathrm{MnZn} / \mathrm{PVC}$ composite at about $900 \mathrm{MHz}$ is also present for composite samples containing carbonyl iron. On the other hand, the second sharp maximum localised above $5 \mathrm{GHz}$ was observed in samples containing only carbonyl iron. These maxima correspond to critical (resonance) frequency $f_{r}$ and are caused by mentioned resonance/relaxation phenomena. In addition, the variation of filler volume ratio in composites changed the magnetocrystalline anisotropy and hence also the values of $\mu$ and $f_{r}[10]$.

High-frequency single-layer electromagnetic wave absorption characteristics of fabricated composites were evaluated by numerical calculation of return loss [8, 9]: $\mathrm{RL}=20 \log |(\mathrm{j} \mu 2 \pi \mathrm{fd} / \mathrm{c}-1) /(\mathrm{j} \mu 2 \pi \mathrm{fd} / \mathrm{c}+1)|$, with $c$ the velocity of light, and $d$ the thickness of the single-layer absorber (backed by a metal sheet). The equation for RL meets the condition $d \ll \lambda$, where $\lambda$ is the wavelength of the incident electromagnetic wave. The absorber (i.e. composite) absorbs the maximum of the energy of the incident electromagnetic wave when $j \mu 2 \pi f d / c=1$. The maximum absorption is then accomplished at a matching thickness $d=d_{m}=c /\left[2 \pi f_{m} \mu^{\prime \prime}\left(f_{m}\right)\right]$, matching frequency 
$f=f_{m}$, and minimum return loss $\mathrm{RL}_{\text {min }}$. Note that $\mu^{\prime \prime}\left(f_{m}\right)$ indicates the value of $\mu^{\prime \prime}$ at $f=f_{m}$.

Figure 3 shows the frequency dependences of return loss RL for fabricated composites. Numerically calculated absorption parameters such as matching thickness $d_{m}$, matching frequency $f_{m}$, the bandwidth $\Delta f$ for $\mathrm{RL} \leq$ $-20 \mathrm{~dB}$ and the minimum of return loss (also known as absorption peak) $\mathrm{RL}_{\text {min }}$ are summarized in Table I. One may note that with the configuration change from twophase MnZn/PVC composite sample to CI/PVC one, the matching thickness $d_{m}$, the matching frequency $f_{m}$ and the bandwidth $\Delta f$ for $\mathrm{RL} \leq-20 \mathrm{~dB}$ decreased while the minimum of return loss $\mathrm{RL}_{\text {min }}$ increased. It is evident that increase of carbonyl iron filler loading (to the detriment of MnZn ferrite filler) in composite structure has a major influence on the decrease of matching thickness i.e. the thickness of the absorber. On the other hand, increasing MnZn filler loading (to the detriment of carbonyl iron filler) leads to the rise of absorption bandwidth.

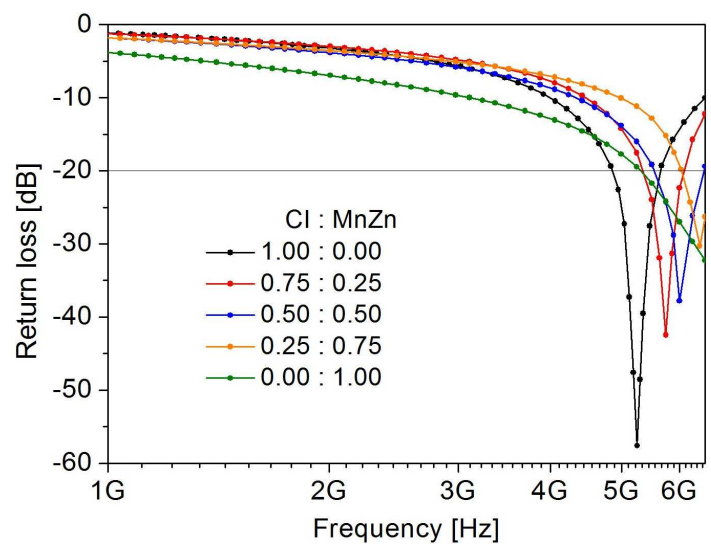

Fig. 3. Frequency dependences of return loss for prepared $\mathrm{CI} / \mathrm{MnZn} / \mathrm{PVC}$ composites with different filler volume ratios.

TABLE I

Absorption parameters for fabricated $\mathrm{CI} / \mathrm{MnZn} / \mathrm{PVC}$ composites of different filler volume ratio CI:MnZn.

\begin{tabular}{c|c|c|c|c}
\hline \hline Ratio & $\begin{array}{c}d_{m} \\
{[\mathrm{~mm}]}\end{array}$ & $\begin{array}{c}f_{m} \\
{[\mathrm{GHz}]}\end{array}$ & $\begin{array}{c}\Delta f[\mathrm{MHz}] \\
(\mathrm{RL} \leq-20 \mathrm{~dB})\end{array}$ & $\begin{array}{c}\mathrm{RL}_{\min } \\
{[\mathrm{dB}]}\end{array}$ \\
\hline 1.00:0.00 & 1.38 & 5.25 & 690 & -57.61 \\
$0.75: 0.25$ & 1.44 & 5.74 & 750 & -42.43 \\
$0.50: 0.50$ & 1.96 & 5.99 & 970 & -37.80 \\
$0.25: 0.75$ & 2.08 & 6.39 & $>1000$ & -30.28 \\
$0.00: 1.00$ & 4.32 & 6.50 & $>1000$ & -
\end{tabular}

The reason for $f_{m}$ (and also $d_{m}$ ) variation in threephase metal/ferrite/polymer composites according to volume ratio of the two-phase metal/ferrite magnetic filler may be found in the basic principles for designing electromagnetic wave absorbers. The relationship between $f_{m}, d_{m}$, and $\mu^{\prime}, \mu^{\prime \prime}$ can be expressed by the following formula $[9]: d_{m} f_{m} \approx(\mu \prime)^{-1 / 2}\left[4\left(1+\tan ^{2}\left(\mu^{\prime \prime} / \mu \prime\right)\right)\right]^{-1}$. This formula states that $d_{m} f_{m}$ value is affected (mainly) by $\mu^{\prime}$ and $\mu^{\prime \prime}$. The variation of $\mu^{\prime}$ and $\mu^{\prime \prime}$ with the change of filler volume ratio of two-phase CI/MnZn filler in $\mathrm{CI} / \mathrm{MnZn} / \mathrm{PVC}$ composites has been caused mainly by the modification of magnetocrystalline anisotropy: $d_{m}$ and $f_{m}$ decreased with the configuration change from $\mathrm{MnZn/PVC}$ composite to CI/PVC one due to the change of $f_{r}$. The fabricated composites show strong microwave absorption in a wide frequency range at small thickness.

\section{Conclusions}

A detailed study was carried out on the electromagnetic wave absorption properties of metal/ferrite/polymer composites with carbonyl iron and manganese-zinc ferrite as two-phase filler and polyvinylchloride as matrix in the broad frequency range $(10 \mathrm{MHz}-6.5 \mathrm{GHz})$. The obtained results showed that the high-frequency absorbing properties are influenced by the strong correlation between return loss and complex permeability of the composites. The absorption peak shifted to the low-frequency region and simultaneously the matching thickness decreases with increasing carbonyl iron volume loading. On the other hand, the absorption bandwidth increases with the rise of $\mathrm{MnZn}$ ferrite filler in composite. The investigated composite materials make it possible to design thin, broadband and flexible microwave absorbers.

\section{Acknowledgments}

This work was supported by the VEGA agency of the Slovak Republic (project no. 1/0405/16), by the University Science Park SUT Bratislava (project IMTS: 26240220084), and by the Slovak Research and Development Agency (contracts no. APVV-0062-11 and APVV-15-0257).

\section{References}

[1] C.H. Phan, M. Mariatti, Y.H. Koh, J. Magn. Magn. Mater. 401, 472 (2016).

[2] Y. Xu, L. Yuan, X. Wang, D. Zhang, J. Alloys Comp. 676, 251 (2016).

[3] S.Y. Zhang, Q.X. Cao, Y.R. Xue, Y.X. Zhou, J. Magn. Magn. Mater. 374, 755 (2015).

[4] F.M. Idris, M. Hashim, Z. Abbas, I. Ismail, R. Nazlan, I.R. Ibrahim, J. Magn. Magn. Mater. 405, 197 (2016).

[5] Y. Qing, W. Zhou, S. Jia, F. Luo, D. Zhu, J. Mater. Sci. Technol. 26, 1011 (2010).

[6] X. Zhang, W. Sun, Cem. Conc. Comp. 32, 726 (2010).

[7] A.M. Gama, M.C. Rezende, C.C. Dantas, J. Magn. Magn. Mater. 323, 2782 (2011).

[8] R. Dosoudil, M. Ušáková, A. Grusková, J. Sláma, IEEE Trans. Magn. 50, 2800204 (2014).

[9] R. Dosoudil, J. Franek, J. Sláma, M. Ušáková, A. Grusková, IEEE Trans. Magn. 48, 1524 (2012).

[10] R. Dosoudil, M. Ušáková, A. Grusková, J. Sláma, Acta Phys. Pol. A 126, 404 (2014). 